\title{
Probing Composition Distributions in Nanoalloy Catalysts with Correlative Electron Microscopy
}

\author{
Shikai Liu, ${ }^{a}$ Isla Gow, ${ }^{\mathrm{b}}$ Thomas Davies, ${ }^{\mathrm{b}}$ Alexandra Barnes, ${ }^{\mathrm{b}}$ Meenakshisundaram Sankar, ${ }^{\mathrm{b}}$ Xiaoxiao \\ Gong, ${ }^{\mathrm{b}}$ Alexander G. Howe, ${ }^{\mathrm{a}}$ Michael Dixon, ${ }^{\mathrm{c}}$ Graham J. Hutchings, ${ }^{\mathrm{b}}$ Christopher J. Kiely, ${ }^{\mathrm{b}, \mathrm{d}}$ and Qian \\ $\mathrm{He}^{\mathrm{a}, *}$

\begin{abstract}
Alloyed nanoparticles are important functional materials and have wide applications especially in heterogeneous catalysis and electrocatalysis. Controlled synthesis of nanoalloys is desirable in order to undertstand their structure-property relationships and further optimize their performance. While many synthesis methods have been developed, information on the resultant composition distributions among particles are often not available, and uniformity of composition from particleto-particle is often incorrectly assumed. Such an analysis would require extensive work on a high-resolution analytical electron microscope, which has some drawbacks and the high-resolution equipment is not always readily accessible. We hereby introduce an alternative way for composition analysis of nanoalloys via a correlative electron microscopy approach, separating the size measurement (imaging) and composition analysis between TEM and SEM instruments. Using a case study of two AuPd nanoalloys which have very similar size distributions but significantly different composition distributions and catalytic activities, we demonstrate both the necessity of performing composition distribution analysis on ultrasmall nanoalloys and the feasibility of this method. We show that a more efficient X-ray analysis on nanoalloys can be done in an SEM due to intrinsically higher ionization cross-sections from the relatively lower energy (e.g. $20 \mathrm{keV}$ ) electron beam and the possibility of using large probe currents and $\mathrm{X}$-ray detectors with large collection angles.
\end{abstract}

\section{Introduction}

Alloyed nanoparticles, often referred to as nanoalloys, ${ }^{1}$ have drawn great research attention due to their interesting chemical, ${ }^{2}$ magnetic ${ }^{3}$ and optical properties. ${ }^{4}$ In particular, nanoalloys have shown promising catalytic performance in many technologically important energy- and environmentrelated processes. ${ }^{5,6}$ Examples include Pd-based nanoalloys for selective hydrogenation ${ }^{7,8}$ and selective oxidation, ${ }^{9,10}$ as well as Pt-based ${ }^{11}$ and $\mathrm{Cu}$-based ${ }^{12}$ nanoalloys for oxygen reduction reactions (ORR) and $\mathrm{CO}_{2}$ reduction reactions, respectively. Nanoalloy catalysts often display so-called synergistic effects that can come from the constituents' (i) electronic interactions, ${ }^{13}$ (ii) strain, ${ }^{14,15}$ (iii) cooperation in the reaction (multi-functionality) ${ }^{16,17}$ and/or (iv) site-separation effects. ${ }^{18}$ Compared to their monometallic counterparts, particle composition serves as an additional parameter for fine-tuning the physical and chemical properties of nanoalloys.

Many synthesis methods have been developed for preparing nanoalloys, ${ }^{19}$ such as co-impregnation, ${ }^{20}$ coreduction, ${ }^{21}$ chemical vapor deposition ${ }^{22,23}$ to name but a few. While their resultant particle size distribution (PSD) are routinely characterized and reported, information regarding the

a. Department of Materials Science and Engineering, National University of Singapore, 9 Engineering Drive 1, Block EA \#03-09, 117575, Singapore. Email: heqian@nus.edu.sg

b. Cardiff Catalysis Institute, Cardiff University, Main Building, Park Pl, Cardiff, CF1O

$3 A T$, United Kingdom

Hitachi High-Technologies Europe, Daresbury, Warrington WA4 4AB, United

Kingdom

d. Department of Materials Science and Engineering, Lehigh University, 5 E Packer

Avenue, Bethlehem, Pennsylvania, 18015, United States composition distributions amongst particles is rarely reported. In other words, compositional uniformity from particle-toparticle is often just assumed. However, the limited amount of experimental work published on this compositional aspect often indicates that this broad assumption is incorrect. For instance, significant composition variations have been observed in $\mathrm{Pt}-\mathrm{Sn}^{24}$ and $\mathrm{Pt}-\mathrm{Rh}^{25}$ catalysts prepared by co-impregnation. Another example is Au-Pd catalysts: when prepared by coimpregnation, larger particles were consistently found to be Aurich while smaller ones were $\mathrm{Pd}$-rich; ${ }^{8,26}$ when prepared by a colloidal route using co-reduction, the opposite composition trend was found. ${ }^{27,28}$ These findings are not surprising as different metal constituents can have very different properties (e.g., reduction potential, bond energies) so that composition distributions can be very sensitive to synthesis conditions, especially when particle sizes are on the nanoscale (i.e., $<10 \mathrm{~nm}$ ) as desired for catalytic applications. Obtaining quantitative information about the composition distribution as a function of particle size is important in order to evaluate and continue improving synthesis methods for nanoalloys. It also helps us to better understand their structure-property relationships and further optimize their catalytic performance.

Such analysis would normally require access to a highperformance analytical electron microscope (AEM), which can simultaneously obtain information about the sizes and the compositions of isolated or supported small nanoalloys (e.g. $<10 \mathrm{~nm}$ ). X-ray Energy Dispersive Spectroscopy (X-EDS) $8,15,26$ is often used as many of the catalytically relevant elements are relatively heavy (i.e., $\mathrm{Pt}, \mathrm{Pd}, \mathrm{Ir}, \mathrm{Au}$ ) although electron energy loss spectroscopy $(E E L S)^{7,29,30}$ can also be used in some cases. With modern aberration-corrected scanning transmission electron 
microscopes (AC-STEM), imaging and analysis of individual particles can be performed down to the atomic-scale. ${ }^{31}$ These high-performance instruments, however, suffer from several disadvantages when trying to collect enough data to generate statistically relevant composition distribution information. Firstly, incident electrons in those types of instrument usually have high kinetic energies (e.g., 200keV), which gives relatively small cross-sections for exciting electronic transitions in the typical energy ranges needed for X-EDS (i.e., $<20 \mathrm{keV}$ ) and EELS (i.e., $<2 \mathrm{keV}$ ) analysis. Secondly, the analysis is also often limited by the possibility of knock-on damage ${ }^{32}$ from the high-energy electrons interacting with the metal nanoparticles and the support materials (e.g., activated carbon, refractory oxides). Although these drawbacks can be partially alleviated by ACSTEMs operating at lower $\mathrm{kV}$ (i.e., 40-60 kV), ${ }^{33}$ the X-ray analysis is usually limited by the tight space available in the STEM for positioning X-ray detectors, which result in poor collection efficiency (i.e., only $<0.1 \%-6 \%$ of total $X$-ray photons emitted are detected). As a result, accurate, quantitative analysis of the particle-to-particle composition distributions in nanoalloy samples can be very challenging and time-consuming, making statistical analysis almost not practical. However, it should be noted that with the very latest generation of AC-STEM instruments, larger X-ray collection angles up to about 2 sr. can now be achieved, ${ }^{34}$ meaning that about $16 \%$ of the $X$-ray photons emitted can be detected. Such high-end instruments are often not accessible to many catalyst researchers for routine analysis of nanoalloy samples.

In this work, we introduce an alternative way of performing statistical analysis of composition- size distributions in nanoalloys that can overcome those drawbacks described above, using a correlative electron microscopy approach. This approach separates the structural characterization (i.e., particle location, structure and size measurement) to a $200 \mathrm{kV}$ Transmission Electron Microscope (TEM), and the composition analysis (X-EDS) of the same particles to a $20 \mathrm{kV}$ Field-Emission Gun Scanning Electron Microscope (FEG-SEM) equipped with a large area silicon drift detector, in order to optimize the efficiency of the compositional analyses. Using AuPd nanoalloys prepared by a colloidal method as an example, we demonstrate both the feasibility of this new approach and the necessity for probing composition-size distributions in nanoalloy catalysts, as this is a key parameter that is often overlooked.

\section{Results and Discussions}

\section{Correlative Electron Microscopy Protocol}

In order to carry out a composition analysis of nanoalloy samples more effectively, it is necessary to improve both the yield and the detection efficiency for characteristic X-rays. Using an SEM that operates below $30 \mathrm{kV}$ can offer three main advantages: Firstly, electrons with lower energy (i.e., <30keV) can give rise to higher ionization cross-sections compared to those at higher energy (i.e., $200 \mathrm{keV}$ ) in high-resolution instruments. This is particularly true for transition metals in

\section{(c)}

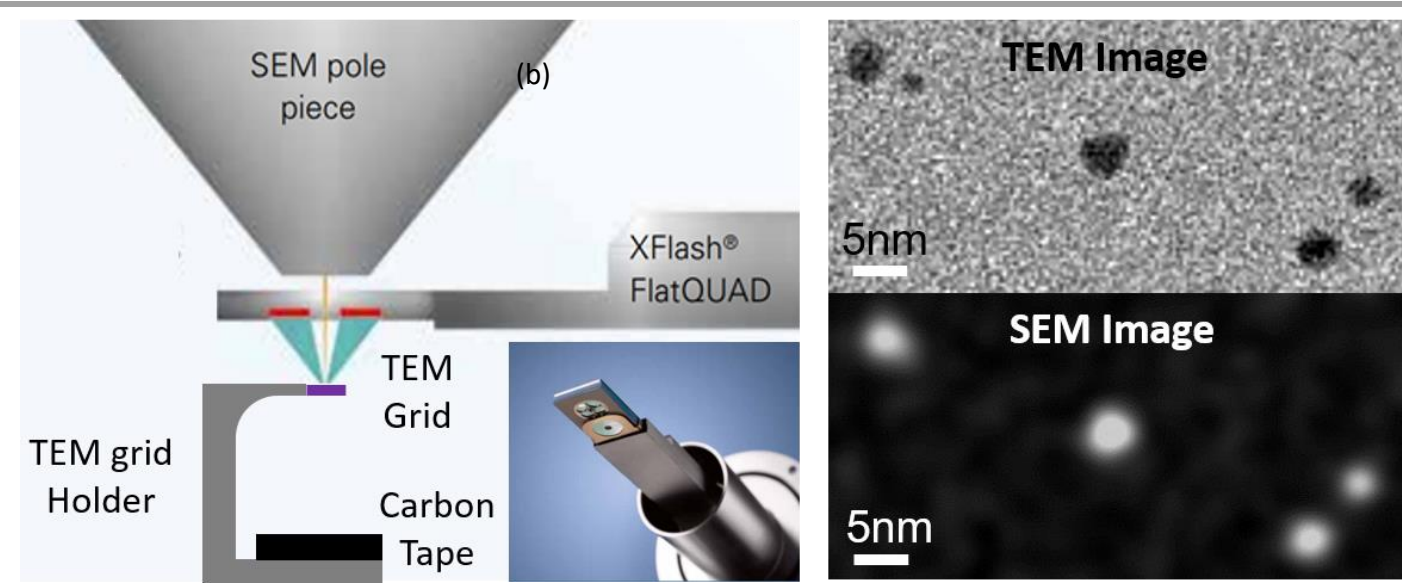

Figure 1 (a) Schematic of the experimental set-up for X-EDS analysis in the Hitachi 8230 Cold-FEG SEM, equipped with a Bruker XFlash ${ }^{\circledR}$ FlatQUAD silicon drift detector (SDD) that is inserted above the specimen. The specimen was the TEM grid that was loaded onto a custom made TEM grid holder made of aluminium. A carbon tape was used to cover the bottom of the holder to minimize stray electrons and X-rays. The inset image (b) shows the FlatQUAD detector, comprising 4-segmented SDDs and a retractable polymer film that is used to protect the SDDs from back-scattered electrons. A representative pair of correlative (c) TEM Bright Field (BF) and (d) SEM secondary electron (SE) images (detected by the in-lens SE detectors). The SE image was low-pass filtered. The white arrow highlighted a small particle about $1 \mathrm{~nm}$ in size that was not visible in the SEM image, possibly because it was located on the opposite side of the film relative to the incident beam direction. (a) and (b) are modified from the schematic shown on Bruker's website with permission. ${ }^{36}$ 
groups 8-11 of the periodic table. According to Llovet et al., ${ }^{35}$ when comparing $20 \mathrm{keV}$ electrons to $200 \mathrm{keV}$ electrons, the ionization cross-sections will be roughly doubled for K-shells in $3 \mathrm{~d}$ metals (e.g., $\mathrm{Fe}, \mathrm{Co}, \mathrm{Ni}$ and $\mathrm{Cu}$ ), and roughly tripled or quadrupled for L-shells in $4 \mathrm{~d}$ metals (e.g., $\mathrm{Ag}, \mathrm{Pd}$ ) and for $\mathrm{M}$ shells in $5 \mathrm{~d}$ metals (e.g., Au). Secondly, electrons with lower energy will cause less or no knock-on damage in the specimen, allowing a larger probe current to be used for better signal generation. According to Egerton, ${ }^{32} 20 \mathrm{kV}$ is below the sputtering threshold energies for most of the elements, except a few metals from groups 1 and 2 of the periodic table. Thirdly, specimens in the SEM are in more open space compared to a high-resolution STEM, potentially allowing larger area X-EDS detectors to be implemented for better signal collection. The drawback is the limited spatial resolution of an SEM, which we show here can be complemented by TEM imaging in a correlative microscopy approach.

Our experimental set-up for studying nanoalloys in a scanning electron microscope is shown schematically in Figure 1(a). The nanoalloy sample (i.e., the colloid drop-cast onto a holey carbon grid) was firstly imaged using a TEM, in order to precisely record the sizes and locations of a representative set (approximately 100-200 in number) of nanoalloy particles. After the TEM characterization, the same grid was cleaned using a UV cleaner (see Materials and Methods) and transferred onto a custom-made aluminium holder for a Hitachi Regulus 8230 SEM equipped with a cold field emission gun. A Faraday cup was also made by drilling a hole $(1 \mathrm{~mm}$ in diameter and more than 10 $\mathrm{mm}$ deep) into this holder so that the electron probe current can be conveniently monitored. The SEM was equipped with a Bruker X-Flash ${ }^{\circledR}$ FlatQUAD X-ED Spectrometer, ${ }^{36}$ which contains four segmented silicon drift detectors (SDD) that are protected from back-scattered electrons by a retractable polymer film arrangement (Figure 1(b)). The electron stopping power of the protective film limited the maximum allowed electron beam energy to be $20 \mathrm{kV}$ in our instrument. During the experiment, the working distance of the specimen was kept at the minimum allowable distance of $10 \mathrm{~mm}$, which provided a good spatial resolution while still allowing the X-EDS detector to be inserted over the specimen. This overhead X-EDS detector provided a relatively large collection solid angle about $1.1 \mathrm{sr} .{ }^{36}$ suggesting that about $9 \%$ of the characteristic $X$-rays emitted can in principle be collected. In order to minimize stray electrons and $\mathrm{X}$-rays, carbon tape was applied to the bottom of the holder as (a) AuPd (PVP)

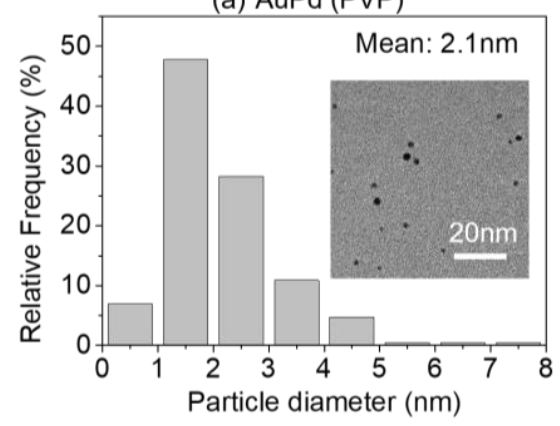

(b) AuPd (PVA)

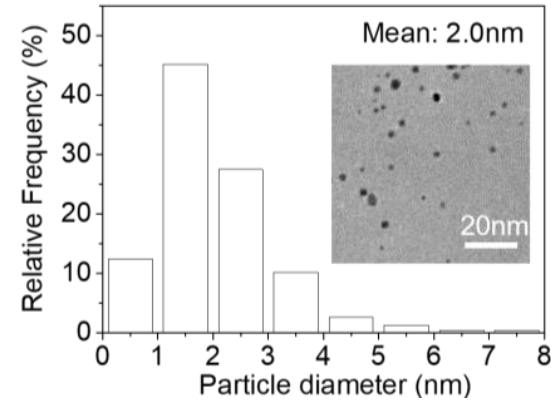

Figure 2 Representative BF-TEM images and the corresponding particle size distributions for the (a) AuPd (PVP) and (b) AuPd (PVA) colloids.

an electron absorber. Figure 1 (c) and (d) show a typical pair of correlative TEM bright-field (BF) and SEM secondary electron (SE) images of same nanoparticles that are less than $5 \mathrm{~nm}$ in diameter. Notice that it is possible that some of the nanoparticles are located on the backside of the carbon film relative to the incident electron beam direction. Those particles are only visible in the TEM BF image but not in SEM SE image (see the particle indicated by a white arrow in Figure $1(c, d)$ ).

\section{Study of AuPd nanoalloy catalysts}

To demonstrate the feasibility of this correlative microscopy approach, two sets of AuPd nanoalloy samples were prepared using a standard colloidal synthesis method that has been previously reported. Au and Pd precursors (Au:Pd wt ratio $=1$ ) in an aqueous solution were reduced quickly using $\mathrm{NaBH}_{4}$, in the presence of a polymer stabilizer, namely polyvinylpyrrolidone

Table 1 Catalytic activities of the $1 \mathrm{wt} \% \mathrm{AuPd} / \mathrm{TiO}_{2}$ (PVP) and $1 \mathrm{wt} \% \mathrm{AuPd} / \mathrm{TiO}_{2}$ (PVA) catalysts in the direct synthesis of $\mathrm{H}_{2} \mathrm{O}_{2}{ }^{\mathrm{a}}$ and $\mathrm{H}_{2} \mathrm{O}_{2}$ hydrogenation ${ }^{\mathrm{b}}$ reactions.

\begin{tabular}{|c|c|c|c|}
\hline Catalyst & $\begin{array}{c}\text { Activity for the direct } \\
\text { synthesis }{ }^{\mathrm{a}} \text { of } \mathrm{H}_{2} \mathrm{O}_{2}\left(\mathrm{~mol}^{-1} \mathrm{H}_{2} \mathrm{O}_{2}\right. \\
\mathrm{h}^{-1} \mathrm{~kg}_{\text {cat }^{-1}}\end{array}$ & $\mathrm{H}_{2} \mathrm{O}_{2}$ selectivity $(\%)^{\mathrm{t}}$ & $\begin{array}{c}\text { Activity for the } \mathrm{H}_{2} \mathrm{O}_{2} \\
\text { hydrogenation }{ }^{\mathrm{c}}\left(\mathrm{mol}^{-1} \mathrm{H}_{2} \mathrm{O}_{2} \mathrm{~h}^{-1}\right. \\
\qquad \mathrm{kg}_{\text {cat }}{ }^{-1}\end{array}$ \\
\hline $1 \mathrm{wt} \% \mathrm{AuPd} / \mathrm{TiO}_{2}$ (PVP) & 26 & 61.7 & 349 \\
\hline $1 w t \%$ AuPd/TiO ${ }_{2}$ (PVA) & 31 & 85.3 & 207 \\
\hline
\end{tabular}

\footnotetext{
a Reaction conditions: $10 \mathrm{mg}$ catalyst in $5.6 \mathrm{~g}$ of methanol and $2.9 \mathrm{~g}$ of water solvent, $420 \mathrm{psi} 5 \% \mathrm{H}_{2} / \mathrm{CO}_{2}+160 \mathrm{psi} 25 \% \mathrm{O}_{2} / \mathrm{CO}_{2}$. Productivity calculated after 30 min of reaction with stirring $1200 \mathrm{rpm}$ at $2^{\circ} \mathrm{C}$.

${ }^{b} \mathrm{H}_{2} \mathrm{O}_{2}$ selectivity was determined by measuring the amount of $\mathrm{H}_{2}$ present after the reaction using gas chromatography.

c Reaction conditions: were the same as those used for $\mathrm{H}_{2} \mathrm{O}_{2}$ synthesis, but in the absence of $160 \mathrm{psi} 25 \% \mathrm{O}_{2} / \mathrm{CO}_{2}$ and with 4 wt $\% \mathrm{H}_{2} \mathrm{O}_{2}$ present in the solvent.

${ }^{c}$ Reaction conditions: were the same as those used for $\mathrm{H}_{2} \mathrm{O}_{2}$ synthesis, but in the absence of $160 \mathrm{psi} 25 \% \mathrm{O}_{2} / \mathrm{CO}_{2}$ and with 4 wt $\% \mathrm{H}_{2} \mathrm{O}_{2}$ present in the solvent.
} 

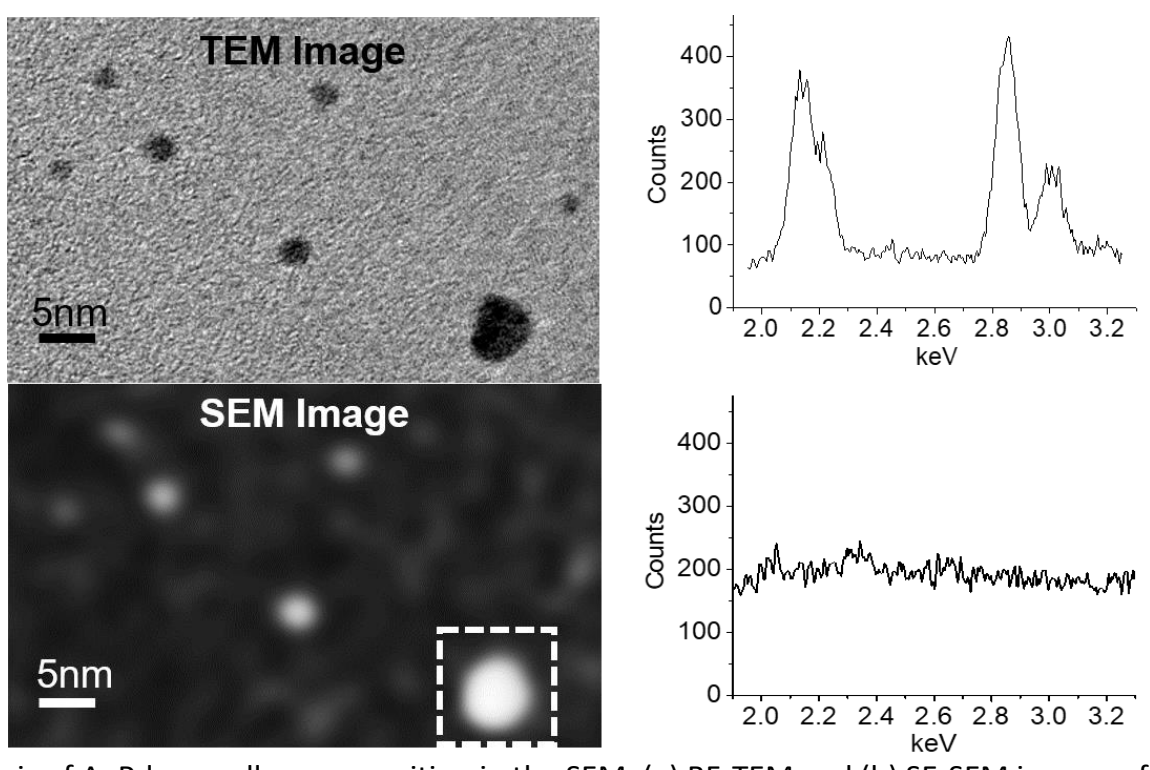

Figure 3 X-EDS analysis of AuPd nanoalloy composition in the SEM. (a) BF-TEM and (b) SE-SEM images of AuPd (PVA) particles from the same area; (c) X-ED spectrum obtained when the beam was scanned over the isolated particle highlighted in (b); (d) $X$-ED spectrum obtained from an identically sized area located nearby but without any visible particles in the BF-TEM or SEMSE images. The SEM image has been low-pass filtered.

(PVP) or polyvinyl alcohol (PVA). The two colloid samples are denoted as AuPd (PVP) and AuPd (PVA), respectively. To make supported catalysts, the requisite amount of colloids was immobilized onto commercial $\mathrm{TiO}_{2}$ support (Degussa, P25) to make $1 \mathrm{wt} \%$ metal loading $\mathrm{AuPd} / \mathrm{TiO}_{2} \quad$ (PVP) and $1 \mathrm{wt} \%$ $\mathrm{AuPd} / \mathrm{TiO}_{2}$ (PVA) catalysts. The catalytic properties of the supported catalysts were evaluated in the direct synthesis of hydrogen peroxide from $\mathrm{H}_{2}$ and $\mathrm{O}_{2}$, as well as the $\mathrm{H}_{2} \mathrm{O}_{2}$ degradation reaction. ${ }^{28}$ The catalytic performances of the two supported catalysts were found to be very different (Table 1). In the direct synthesis reaction, $1 \mathrm{wt} \% \mathrm{AuPd} / \mathrm{TiO}_{2}$ (PVP) gives slightly lower activity $\left(26\right.$ mol $^{-1} \mathrm{H}_{2} \mathrm{O}_{2} \mathrm{~h}^{-1}$ kgcat $^{-1}$ ) and $\mathrm{H}_{2} \mathrm{O}_{2}$ selectivity (61.7\%) compared to the $1 \mathrm{wt} \% \mathrm{AuPd} / \mathrm{TiO}_{2}$ (PVA) catalyst (activity - 31 mol-1 $^{-1} \mathrm{H}_{2} \mathrm{O}_{2} \mathrm{~h}^{-1}$ kgcat $_{-1}, \mathrm{H}_{2} \mathrm{O}_{2}$ selectivity 85.3\%). In the $\mathrm{H}_{2} \mathrm{O}_{2}$ degradation reaction, the $1 \mathrm{wt} \% \mathrm{AuPd} / \mathrm{TiO}_{2}$ (PVP) material showed an almost $70 \%$ higher activity $\left(349 \mathrm{~mol}^{-1}\right.$ $\mathrm{H}_{2} \mathrm{O}_{2} \mathrm{~h}^{-1} \mathrm{~kg}_{\text {cat }}{ }^{-1}$ ) compared to that of $1 \mathrm{wt} \% \mathrm{AuPd} / \mathrm{TiO}_{2}$ (PVA) (207 $\mathrm{mol}^{-1} \mathrm{H}_{2} \mathrm{O}_{2} \mathrm{~h}^{-1} \mathrm{~kg}_{\text {cat }^{-1}}{ }^{-1}$, which are consistent with their different $\mathrm{H}_{2} \mathrm{O}_{2}$ selectivities exhibited in the direct synthesis reaction. In this work, we introduce an alternative way of performing statistical analysis.

The two parent AuPd colloids were characterized using TEM, from which the corresponding particle size distributions were obtained by analyzing more than 200 particles for each sample (using the method shown in Supplementary Information, Figure S1). The particle size distribution histogram and representative TEM-BF images of each sample are shown in Figure 2. Both AuPd (PVP) and AuPd (PVA) have very similar size distributions, with average particle sizes of $2.1 \mathrm{~nm}$ and $2.0 \mathrm{~nm}$ respectively. The overall compositions of the AuPd colloid samples were determined using inductively coupled plasma atomic emission spectroscopy (ICP-AES), and the two AuPd nanoalloys were found to have very similar overall compositions, with $\mathrm{Pd}: \mathrm{Au}$ weight ratios of 0.98 and 1.05 for the AuPd (PVP) and AuPd (PVA) materials respectively. According to our previous study on composition-dependent activities of AuPd nanoparticles, ${ }^{37}$ we can be confident that the considerably different catalytic activities noted for the two AuPd/TiO 2 nanoalloy materials is unlikely to be due to such small differences in both mean particle size and averaged sample composition.

The correlative microscopy approach described above was then used to study the composition variation as a function of particle size in these two nanoalloys. A representative area that was imaged using both TEM and SEM is shown in Figure 3 (a) and (b), respectively. The SEM was operated at a relatively high probe current (about 500-600 pA as measured by the Faraday cup) while still maintaining a reasonable image resolution so that the smallest particles are still visible in the secondary electron images. To analyze the composition of an individual particle, the electron beam was continuously scanned over an area that only covers the selected particle (see box delineated in Figure 3 (b)) while the X-rays emitted were collected by the overhead SD detectors. The acquisition time varied from 60 seconds to 180 seconds per particle. Figure 3(c) shows part of the X-ED spectrum obtained from the particle highlighted in Figure 3(b), with clear peaks visible for the Au M ( 2.1 keV) and $\mathrm{Pd} \mathrm{L}(\sim 2.8 \mathrm{keV})$ characteristic X-ray signals. A background spectrum was also acquired from a nearby support area without any visible particles (in both the SEM and TEM images). As shown in Figure $3(\mathrm{~d})$, no detectable Au M or Pd L peaks were found from this latter area, suggesting the contribution from stray electrons and $\mathrm{X}$-rays is negligible. The spectra were smoothed and subjected to background removal before the peak intensities were integrated (see Figure S2). The resultant X-ED spectra were then quantified using the Cliff-Lorimer method $^{38}$ (details are given in Materials and Methods). Several X-ED spectra obtained by scanning relatively larger areas containing hundreds of particles were averaged and served as an internal standard, assuming that they represent the average compositions of the AuPd (PVA) and AuPd (PVP) samples measured by independent ICP-AES analysis (Supplementary Information, Figure S3 and Table S1). 
The quantified compositions (measured in the SEM) of individual particles were then plotted as a function of particle size (as measured in the TEM) for the AuPd (PVP) and AuPd (PVA) nanoalloys as shown in Figure 4 (a) and (b) respectively. The error bars represent a $99 \%$ confidence interval. In a typical analysis, over 10,000 counts can be collected in a characteristic peak from an individual particle about 3-4 $\mathrm{nm}$ in size over a 3 minutes time interval so that the uncertainties according to Poisson counting statistics are less than $1 \%$. This represents an order of magnitude improvement when compared to previous work using high-resolution analytical electron microscopy. ${ }^{8,} 26$ Alternatively, shorter acquisition time can be employed, allowing more particles to be analyzed in a given time period so that the composition distribution better represents the nanoalloy population. From Figure 4 (a) and (b), it can be first seen that for both samples, particle compositions vary significantly for particles with similar sizes. For instance, the compositions for particles of $3 \mathrm{~nm}$ in both samples can vary from about 40 at\% Pd to more than 70 at\% Pd. Another interesting finding is that the two samples also show a distinctly different size-dependency of the particle composition: the AuPd (PVP) sample shows a more random composition distribution across particles with different sizes, whereas the AuPd (PVA) sample displays a definite systematic size-dependent composition variation. To better visualize the trends, Figure 4 (c) and (d) show the corresponding averaged compositions of particles over a cert(aih size range, obtained from the data shown in Figure 4(a) and (b) respectively. The vertical bars represent a $90 \%$ confidence interval calculated using the $\mathrm{t}$ - distribution. The horizontal bars represent the size range over which the compositional data were averaged. For the AuPd (PVP) sample, it is clearer in this view that the averaged compositions are almost constant across the $1-8 \mathrm{~nm}$ size range and they are reasonably close to the nominal value of 65 at\% Pd and 35 at\% $\mathrm{Au}$. The size-dependent composition variation in the AuPd (PVA) sample is more evident in Figure 4(d). For smaller particles, the average Pd content was found to be below 60 at\%, while for the larger particles, the Pd content was approaching 75at\%.

Previous studies on the direct synthesis of $\mathrm{H}_{2} \mathrm{O}_{2}$ using supported AuPd nanoalloys have indicated that both the activity and selectivity are sensitive to the catalyst composition. ${ }^{38}$ Since the mean particle size and the overall nominal composition of the AuPd (PVP) and AuPd (PVA) materials are very similar, it is reasonable to hypothesize that the measured differences in the catalytic activity may originate from differences in the composition variations that can occur from particle-to-particle. The finding that two AuPd colloids made by very similar methods, except using different polymer stabilizers (i.e., PVA and PVP), can have very different composition distributions as a function of particle size is noteworthy and consistent with our previous reports based on complementary on aberration-corrected AEM analyses. ${ }^{8,26-28,37}$ For instance, in the study of Pritchard et al., ${ }^{37}$ we have observed Pd segregation in larger particles for a AuPd (PVA) colloid (bsjample, and such a phenomenon was not observed for the AuPd (PVP) sample in a later study by Agarwal et al. ${ }^{8}$ Compared to those studies, in which only 20-30 particles of the population
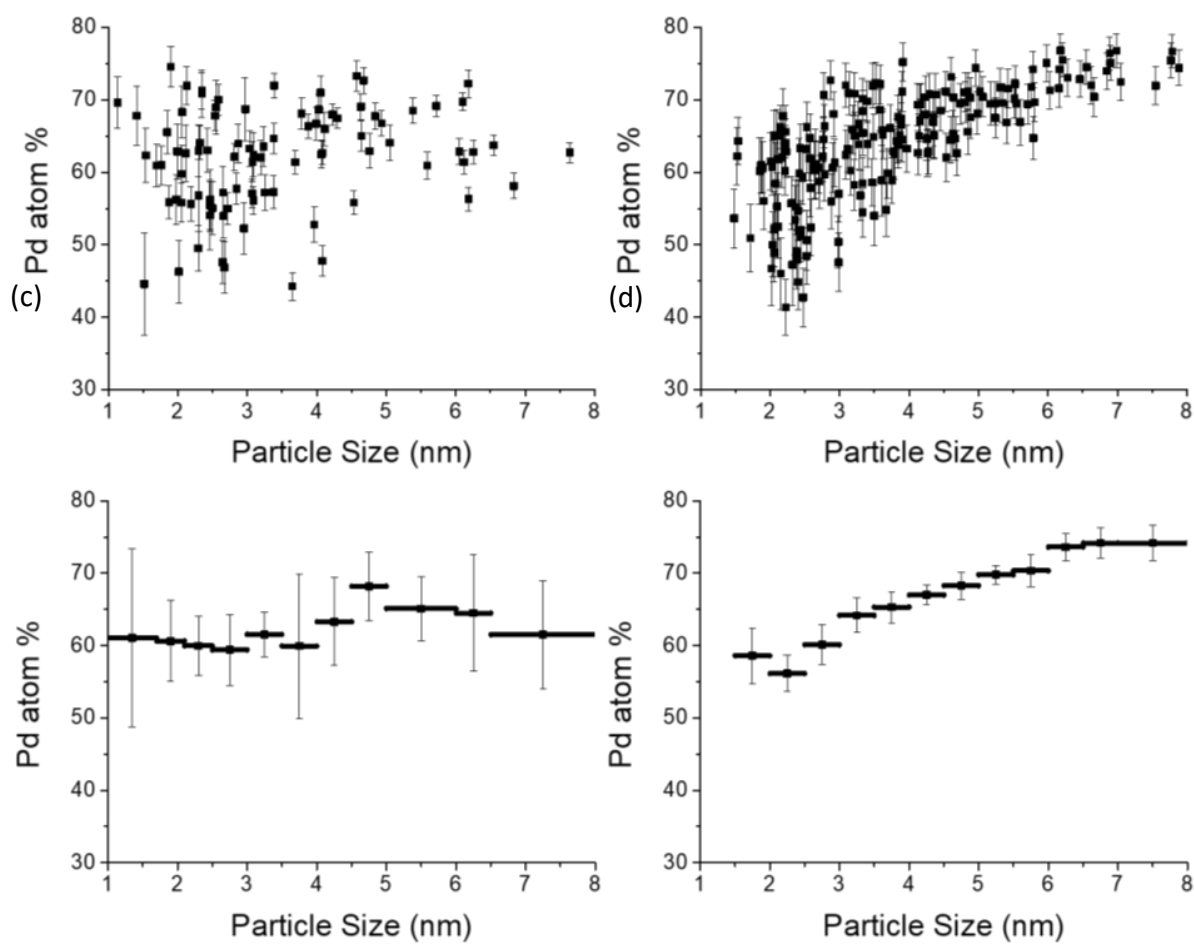

Figure 4 Composition versus particle size measurements of the AuPd colloids as determined using the correlative electron microscopy approach. (a), (b) show the compositions of individual nanoparticles (measured by X-EDS in the SEM) plotted against their particle sizes (measured by TEM) for both the AuPd (PVP) and AuPd (PVA) colloids. About 100-200 particles were analysed in each case. The error bars in (a) and (b) represent 99\% confidence intervals. (c) and (d) represent the 'averaged' particle composition as a function of particle size intervals, derived from the data shown in (a) and (b). The horizontal bars represent the particle size binning range over which the compositions were averaged. The vertical bars represent $90 \%$ confidence intervals calculated using the t-distribution. 
was analyzed, here we analyzed between and 100 and 200 particles in each case, and the observed trend is more reliable and statistically significant. The reason why simply changing polymer stabilizers can give rise to such different trends in composition versus particle size is currently unclear and is still a matter for debate. Alloyeau et al. ${ }^{39}$ have reported that similar size-dependent composition distributions can be caused by a selective Ostwald Ripening process, in which one element undergoes ripening faster than the other. It is conceivable that a similar Ostwald ripening process has occurred more prolifically during colloid synthesis for the PVA ligand variant compared to the PVP stabilized particles due to subtle differences in the PVA and PVP ligand binding strengths. Nevertheless, this finding shows that even small changes in synthesis protocols can result in significant changes to the compositional uniformity displayed by the resultant nanoalloys, which in turn can affect their catalytic properties This study clearly demonstrates the necessity of performing additional individual particle composition analyses (as a matter of routine) alongside the standard particle size distribution analyses when characterizing nanoalloy particle populations.

\section{Some additional practical considerations}

The feasibility and advantages of this correlative microscopy approach for characterizing colloidal nanoalloy particle populations have been clearly demonstrated through this study. In practice, we found that the most challenging practical aspect to overcome was the hydrocarbon contamination that can build up on the sample during the prolonged X-EDS analysis in the SEM chamber, which usually has a poorer vacuum (i.e., 10-4 Pa) compared to a high-resolution STEM instrument (i.e., < 10-5 Pa). If contamination does build-up, the particles can no longer be identified by SE imaging, so that extended analysis cannot take place. A UV cleaner was therefore used to treat the TEM grid before commencing the SEM experiment, which does slightly heat up the TEM grid. In addition, an electron scan with relatively large probe current could also induce heating. In order to see if these will induce unwanted particle growth, BF-TEM imaging was used to check the sample before and after the UV cleaning and EDS analysis. Indeed, some particle sintering occurred if the particles were in very close proximity in the first place. However, for particles that were initially reasonably well separated from each other, (which were the ones we would always select to perform SEM-XEDS analysis on), no particle growth was observed due to the UV treatment and then the XEDS analysis in the SEM (see Figure S4). Another noteworthy feature of this correlative method is that it works best for sub$10 \mathrm{~nm}$ nanoalloy particles, since (i) this is the size range where the particles were difficult to analyze quantitatively using highresolution analytical electron microscopes and thus could benefit the most from this new approach; and (ii) with larger particles, significant beam broadening can occur that could potentially create bias in the composition analysis, especially when there are segregation effects occurring in these bimetallic particles. To illustrate the second point, a Monte Carlo simulation ${ }^{40}$ was carried out using $20 \mathrm{keV}$ electrons, a $1 \mathrm{~nm}$ probe size and the target consisted of a series of Au nanocubes of $20,10,5$, and $2 \mathrm{~nm}$ in size. As shown in Figure S5, when the particles get larger, the extent of beam broadening becomes more obvious.

\section{Conclusions}

A correlative electron microscopy approach has been developed for analyzing the composition distributions that can exist in nanoalloy populations, a key parameter that has been largely overlooked in most previous catalyst characterisation studies of such nanomaterials. We have shown using this approach that two AuPd colloids, differing only in protective ligand identity, can exhibit very different composition versus particle size trends that result in different catalytic performance characteristics properties. The benefits of using this correlative electron microscopy approach arise primarily from more efficient $\mathrm{X}$-ray analysis of nanoalloy composition using relatively low energy electrons (i.e., 20kV), which have larger ionization cross-sections. The technique also permits the use of higher probe currents due to the absence of knock-on damage at lower electron energies (e.g. 20keV), which also gives rise to better counting statistics through improved signal generation. Furthermore, the current method can potentially be still further improved with better X-EDS detector design that takes full advantage of the available space around the sample and a better SEM chamber vacuum. Finally, the combined cost of a cold-FEG SEM and a large X-EDS detector such as a FlatQuad are still much lower compared to a multimillion-dollar aberrationcorrected analytical electron microscope. Compared to other techniques such as atom probe tomography, ${ }^{41-46}$ the current approach does not require special sample preparation for small nanoalloys (e.g. making a tip-shaped specimen in which the particles are embedded). Therefore, we believe the technique described in this paper should, in general, be more accessible to researchers interested in the structural and compositional analysis of individual nanoalloy particles and can help to promote more routine composition distribution analysis of nanoalloys. Through such studies, highly relevant insights into structure/performance relationships will emerge, which could result in synthesis technique improvements that lead to further optimised nanoalloy catalyst performance.

\section{Experimental}

\section{Synthesis of AuPd nanoalloy particles and $\mathrm{AuPd} / \mathrm{TiO}_{2}$ supported catalysts}

The AuPd alloy nanoparticles were prepared using a previously reported colloidal synthesis method.9 The requisite amount of an aqueous solution of $\mathrm{HAuCl} 4$ and an acidified solution of $\mathrm{PdCl}_{2}$ (in $0.5 \mathrm{M} \mathrm{HCl}$ ) were mixed in $400 \mathrm{~mL}$ of de-ionized water so that the total amounts of $\mathrm{Pd}$ and $\mathrm{Au}$ in the solution are $5 \mathrm{mg}$ each. Next $12 \mathrm{mg}$ of pre-dissolved polyvinylpyrrolidone (PVP, average molecular weight $10,000 \mathrm{~g} / \mathrm{mol}$, Sigma Aldrich) or polyvinyl alcohol (PVA, average molecular molar weight 10,000 g/mol, Sigma Aldrich) were added as stabilizers to give a metal-topolymer weight ratio of 1:1.2. After 2-3 mins of stirring, $3.62 \mathrm{ml}$ of a freshly prepared $0.1 \mathrm{M}$ aqueous solution of sodium 
borohydride $\left(\mathrm{NaBH}_{4}\right.$, Sigma Aldrich) was quickly injected, so that the molar ratio of $\mathrm{NaBH} 4-$ to-metal was 5:1. After the injection process, the metal precursor solution rapidly changed colour to dark brown, which indicated the formation of colloidal AuPd nanoparticles. The aqueous solution was then stirred for an additional $30 \mathrm{~min}$ in the air before being stored.

For making supported catalysts, the pre-synthesised AuPd (PVA) or AuPd (PVP) colloids were immobilized onto a commercial $\mathrm{TiO}_{2}$ support material consisting of a mixture of rutile and anatase phases (P25, Degussa, 1.98g). A sufficient amount of support material was added into the stirred colloidal solution to achieve a $1 \mathrm{wt} \%$ total metal loading. The solution was acidified to $\mathrm{pH}=1-2$ using sulphuric acid to achieve a more homogeneous spatial deposition of nanoparticles. The mixture was then stirred for $1 \mathrm{~h}$ until the supernatant solution became clear, indicating the deposition process was complete. The AuPd/TiO catalyst was then filtered and washed with $2 \mathrm{~L}$ of distilled water to remove excess contaminants and dried in an oven at $110^{\circ} \mathrm{C}$ for $16 \mathrm{~h}$.

\section{The Direct Synthesis of Hydrogen Peroxide $\left(\mathrm{H}_{2} \mathrm{O}_{2}\right)$}

The $\mathrm{AuPd} / \mathrm{TiO}_{2}$ (PVA) and $\mathrm{AuPd} / \mathrm{TiO}_{2}$ (PVP) catalysts were evaluated for the direct synthesis of $\mathrm{H}_{2} \mathrm{O}_{2}$ using a stainless-steel autoclave (Parr Instruments) with a nominal volume of $100 \mathrm{~mL}$ and a maximum working pressure of $14 \mathrm{MPa}$. The autoclave was equipped with an overhead stirrer (0-2000 rpm) and had provision for measurement of temperature and pressure. For the standard reaction conditions, the autoclave was charged with the catalyst $(0.01 \mathrm{~g})$ and solvent $(5.6 \mathrm{~g} \mathrm{MeOH}$ and $2.9 \mathrm{~g}$ $\mathrm{H}_{2} \mathrm{O}$ ), and purged three times with $5 \% \mathrm{H}_{2} / \mathrm{CO}_{2}(3 \mathrm{MPa}$ ) and then filled with $5 \% \quad \mathrm{H}_{2} / \mathrm{CO}_{2}$ and $25 \% \quad \mathrm{O}_{2} / \mathrm{CO}_{2}$ to give a hydrogen/oxygen ratio of $1: 2$ at a total pressure of $3.7 \mathrm{MPa}$. Stirring (at $1200 \mathrm{rpm}$ ) was commenced upon reaching the desired temperature at $2^{\circ} \mathrm{C}$, and experiments were carried out for $30 \mathrm{~min}$. The $\mathrm{H}_{2} \mathrm{O}_{2}$ yield was determined by titration of aliquots of the final filtered solution with acidified $\mathrm{Ce}\left(\mathrm{SO}_{4}\right)_{2}$ $\left(7 \times 10^{-3} \mathrm{~mol} / \mathrm{L}\right)$. The $\mathrm{Ce}\left(\mathrm{SO}_{4}\right)_{2}$ solutions were standardized against $\left(\mathrm{NH}_{4}\right)_{2} \mathrm{Fe}\left(\mathrm{SO}_{4}\right)_{2} .6 \mathrm{H}_{2} \mathrm{O}$ using ferroin as the indicator. The catalytic conversion of $\mathrm{H}_{2}$ and selectivity towards $\mathrm{H}_{2} \mathrm{O}_{2}$ were determined using a Varian $3800 \mathrm{GC}$ fitted with TCD and equipped with a Porapak $\mathrm{Q}$ column. The $\mathrm{H}_{2}$ conversion and $\mathrm{H}_{2} \mathrm{O}_{2}$ selectivity were defined as follows:

$$
\begin{gathered}
\mathrm{H}_{2} \text { Conversion }(\%)=\frac{\mathrm{mmol}_{\mathrm{H} 2(\mathrm{t}(0))}-\mathrm{mmol}_{\mathrm{H} 2(\mathrm{t}(1))}}{\mathrm{mmol}_{\mathrm{H} 2(\mathrm{t}(0))}} \times 100 \\
\mathrm{H}_{2} \mathrm{O}_{2} \text { Selectivity }(\%)=\frac{\mathrm{H}_{2} \mathrm{O}_{2} \text { detected }(\mathrm{mmol})}{\mathrm{H}_{2} \text { consumed }(\mathrm{mmol})} \times 100
\end{gathered}
$$

\section{$\mathrm{H}_{2} \mathrm{O}_{2}$ Hydrogenation Test}

$\mathrm{H}_{2} \mathrm{O}_{2}$ hydrogenation experiments were also carried out in a similar manner to that described above for the direct synthesis of $\mathrm{H}_{2} \mathrm{O}_{2}$ but in the absence of $1.1 \mathrm{MPa} 25 \% \mathrm{O}_{2} / \mathrm{CO}_{2}$. In a typical test run, the autoclave was charged with catalyst $(0.01 \mathrm{~g})$ and a solution containing 4 wt\% $\mathrm{H}_{2} \mathrm{O}_{2}\left(5.6 \mathrm{~g} \mathrm{MeOH}, 2.22 \mathrm{~g} \mathrm{H}_{2} \mathrm{O}\right.$, and $\left.0.68 \mathrm{~g} \mathrm{H}_{2} \mathrm{O}_{2}(50 \%)\right)$. The charged autoclave was then purged three times with $5 \% \mathrm{H}_{2} / \mathrm{CO}_{2}(0.7 \mathrm{MPa})$ before filling with $5 \%$ $\mathrm{H}_{2} / \mathrm{CO}_{2}$ to a pressure of $2.9 \mathrm{MPa}$ at $20^{\circ} \mathrm{C}$. The temperature was then dropped to $2^{\circ} \mathrm{C}$ using an ice bath, followed by stirring (at $1200 \mathrm{rpm}$ ) of the reaction mixture for $30 \mathrm{~min}$. The amount of residual $\mathrm{H}_{2} \mathrm{O}_{2}$ present after the reaction was determined using the titration method described above.

\section{Transmission Electron Microscopy}

A JEOL 2100 TEM with a $\mathrm{LaB}_{6}$ gun operating at $200 \mathrm{kV}$ was used to image the as-prepared AuPd-PVA and AuPd-PVP colloidal particles. The TEM specimen was prepared by depositing the aqueous AuPd colloid solution onto a holey carbon grid and allowing the solvent to evaporate. The grids were obtained from SPI Supplies and Ted Pella. They are not finder grids but do have recognizable features in the centre, which were used to locate particles (an example is given in Figure $\mathrm{S} 6$ in the Supplementary Information). A systematic series of higher and lower magnification images of the nanoparticles were recorded in order to measure particle size and record their precise locations on the TEM grid. Particle size distributions were determined using the auto-local threshold and the particle analysis functions in ImageJ.

\section{Scanning Electron Microscopy and X-ray Energy Dispersive Spectroscopy}

A Hitachi SU-8230 SEM equipped with cold field emission gun was used to image the same set of AuPd particles that were previously located and characterised in the TEM. A customized sample holder was used to hold the TEM grids close to the objective lens, and a thick carbon tape was used at the bottom of the holder to minimize stray electrons and X-rays. Prior to SEM analysis, the TEM grids were cleaned using a Hitachi ZONE II tabletop UV specimen cleaner in order to minimize contamination during the subsequent SEM experiments.

X-ray Energy Dispersive Spectroscopy (X-EDS) of individual particles was performed using a Bruker XFlash ${ }^{\circledR}$ FlatQUAD silicon drift detector, which was inserted between the SEM polepiece and the sample, allowing a collection solid angle of $\sim 1.1$ sr.. X-EDS quantification was carried out using the CliffLorimer method, in which the average composition of several hundred of particles was used as an internal standard, assuming that they have the same composition as was independently determined by ICP-AES analysis of the same specimen. The XEDS spectrum was smoothed and background-subtracted before integrating the areas of the Au M peak (2.03-2.26 keV) and Pd L peak (2.75-3.08 keV). The estimation of errors for the compositions measured of individual particles was done by following by a modified procedure described in reference 37 . The errors associated with the Cliff-Lorimer k-factor was estimated using the following formula:

$$
\frac{\Delta k}{k}=\sqrt{\left(\frac{\Delta I_{A u}}{I_{A u}}\right)^{2}+\left(\frac{\Delta I_{P d}}{I_{P d}}\right)^{2}+\left(\frac{\Delta M_{P d}}{M}\right)^{2}+\left(\frac{\Delta M_{A u}}{M_{A u}}\right)^{2}}
$$

where $\Delta I_{A u}=3 \sqrt{I_{A u}}, \Delta I_{P d}=3 \sqrt{I_{P d}}$ are the Poisson counting uncertainties at $99 \%$ interval. $\left(\Delta M_{-} P d\right) / M_{-} P d$ and $\left(\Delta M \_A u\right) / M \_A u$ are the estimated relative error from ICP-AES analysis for Pd and $\mathrm{Au}$. (Table S1) 
The error in composition was then estimated using the following formula:

$\triangle C_{P d}$

$=\sqrt{\left(C_{P d}(\Delta k)-C_{P d}\right)^{2}+\left(C_{P d}\left(\Delta I_{A u}\right)-C_{P d}\right)^{2}+\left(C_{P d}\left(\Delta I_{P d}\right)-C_{P d}\right)^{2}}$

The first term is the maximum error that the uncertainty of $k$ factor could cause to the composition, while the second and third terms are the maximum errors that counting uncertainties in the Au M peak and $\mathrm{Pd} \mathrm{L}$ peak could contribute, respectively.

$\Delta I_{A u}=3 \sqrt{I_{A u}}$ and, $\Delta I_{P d}=3 \sqrt{I_{P d}}$, represents a $99 \%$ confidence interval.

\section{Inductively coupled plasma - atomic emission spectroscopy (ICP- AES)}

ICP-AES analysis was performed using an Atom Scan 16 instrument (TJA Corporation). The AuPd/TiO 2 catalysts were digested using aqua regia. The solution was then filtered and diluted down to a metal concentration of about 10 ppm before being tested.

\section{Conflicts of interest}

There are no conflicts to declare.

\section{Acknowledgements}

Qian He would like to acknowledge the support by National Research Foundation (NRF) Singapore, under its NRF Fellowship (NRFF11-2019-0051). H.Q. would like to acknowledge the Cardiff Catalysis Institute (CCI) (for access to the synthesis lab, catalytic testing lab, and TEM facilities) and the Institute of Compound Semiconductors (ICS), for SEM access. H.Q. would also like to acknowledge technical support from Hitachi through the loan of a ZONE II UV sample cleaner.

\section{Notes and References}

R. Ferrando, J. Jellinek and R. L. Johnston, Chem. Rev., 2008, 108, 845-910.

2 M. Sankar, N. Dimitratos, P. J. Miedziak, P. P. Wells, C. J. Kiely and G. J. Hutchings, Chem. Soc. Rev., 2012, 41, 80998139.

3 D. Alloyeau, C. Ricolleau, C. Mottet, T. Oikawa, C. Langlois, Y. Le Bouar, N. Braidy and A. Loiseau, Nat. Mater., 2009, 8, 940-946.

4 H. Garcia, R. Sachan and R. Kalyanaraman, Plasmonics, 2012, 7, 137-141.

5 A. K. Singh and Q. Xu, ChemCatChem, 2013, 5, 652-676.

6 C. Kim, F. Dionigi, V. Beermann, X. Wang, T. Möller and P. Strasser, Adv. Mater., 2019, 31, e1805617.

7 S. J. Freakley, Q. He, J. H. Harrhy, L. Lu, D. A. Crole, D. J. Morgan, E. N. Ntainjua, J. K. Edwards, A. F. Carley, A. Y. Borisevich, C. J. Kiely and G. J. Hutchings, Science, 2016, 351, 965-968.

8 J. K. Edwards, B. Solsona, E. Ntainjua N, A. F. Carley, A. A. Herzing, C. J. Kiely and G. J. Hutchings, Science, 2009, 323, 1037-1041.

9 N. Agarwal, S. J. Freakley, R. U. McVicker, S. M. Althahban,
N. Dimitratos, Q. He, D. J. Morgan, R. L. Jenkins, D. J. Willock, S. H. Taylor, C. J. Kiely and G. J. Hutchings, Science, 2017, 358, 223-227.

L. Kesavan, R. Tiruvalam, M. H. A. Rahim, M. I. Bin Saiman, D. I. Enache, R. L. Jenkins, N. Dimitratos, J. A. LopezSanchez, S. H. Taylor, D. W. Knight, C. J. Kiely and G. J. Hutchings, Science, 2011, 331, 195-199.

X. X. Wang, M. T. Swihart and G. Wu, Nat. Catal., 2019, 2, 578-589.

A. Vasileff, C. Xu, Y. Jiao, Y. Zheng and S. Z. Qiao, Chem, 2018, 4, 1809-1831.

N. Holmberg, K. Laasonen and P. Peljo, Phys. Chem. Chem. Phys., 2016, 18, 2924-2931.

S. Zhang, X. Zhang, G. Jiang, H. Zhu, S. Guo, D. Su, G. Lu and S. Sun, J. Am. Chem. Soc., 2014, 136, 7734-7739.

X. Wang, S. II Choi, L. T. Roling, M. Luo, C. Ma, L. Zhang, M. Chi, J. Liu, Z. Xie, J. A. Herron, M. Mavrikakis and Y. Xia, Nat. Commun., 2015, 6, 7594.

M. D. Marcinkowski, M. T. Darby, J. Liu, J. M. Wimble, F. R. Lucci, S. Lee, A. Michaelides, M. Flytzani-Stephanopoulos, M. Stamatakis and E. C. H. Sykes, Nat. Chem., 2018, 10, 325-332.

G. Kyriakou, M. B. Boucher, A. D. Jewell, E. A. Lewis, T. J. Lawton, A. E. Baber, H. L. Tierney, M. FlytzaniStephanopoulos and E. C. H. Sykes, Science, 2012, 335, 1209-1212.

F. Gao and D. W. Goodman, Chem. Soc. Rev., 2012, 41, 8009-8020.

K. D. Gilroy, A. Ruditskiy, H.-C. Peng, D. Qin and Y. Xia, Chem. Rev., 2016, 116, 10414-10472.

J. K. Edwards, A. F. Carley, A. A. Herzing, C. J. Kiely and G. J. Hutchings, Faraday Discuss., 2008, 138, 225-239. D. Wang and Y. Li, Adv. Mater., 2011, 23, 1044-1060. J. Lu, K. Bin Low, Y. Lei, J. A. Libera, A. Nicholls, P. C. Stair and J. W. Elam, Nat. Commun., 2014, 5, 3264. M. M. Forde, L. Kesavan, M. I. Bin Saiman, Q. He, N. Dimitratos, J. A. Lopez-Sanchez, R. L. Jenkins, S. H. Taylor, C. J. Kiely and G. J. Hutchings, ACS Nano, 2014, 8, 957-969. L. Bednarova, C. E. Lyman, E. Rytter and A. Holmen, J. Catal., 2002, 211, 335-346. R. E. Lakis, Y. Cai, H. G. Stenger and C. E. Lyman, J. Catal., 1995, 154, 276-287.

26 A. A. Herzing, M. Watanabe, J. K. Edwards, M. Conte, Z. R. Tang, G. J. Hutchings and C. J. Kiely, Faraday Discuss., 2008, 138, 337-351.

Q. He, P. J. Miedziak, L. Kesavan, N. Dimitratos, M. Sankar, J. A. Lopez-Sanchez, M. M. Forde, J. K. Edwards, D. W. Knight, S. H. Taylor, C. J. Kiely and G. J. Hutchings, Faraday Discuss., 2013, 162, 365-378.

M. Sankar, Q. He, M. Morad, J. Pritchard, S. J. Freakley, J. K. Edwards, S. H. Taylor, D. J. Morgan, A. F. Carley, D. W. Knight, C. J. Kiely and G. J. Hutchings, ACS Nano, 2012, 6, 6600-6613. H. L. Xin, J. A. Mundy, Z. Liu, R. Cabezas, R. Hovden, L. F. Kourkoutis, J. Zhang, N. P. Subramanian, R. Makharia, F. T. Wagner and D. A. Muller, Nano Lett., 2012, 12, 490-497. L. Han, Q. Meng, D. Wang, Y. Zhu, J. Wang, X. Du, E. A. Stach and H. L. Xin, Nat. Commun., 2016, 7, 13335. A. Varambhia, L. Jones, A. London, D. Ozkaya, P. D. Nellist and S. Lozano-Perez, Micron, 2018, 113, 69-82. R. F. Egerton, P. Li and M. Malac, Micron, 2004, 35, 399409. 

Pennycook, K. Suenaga and V. Nicolosi, Ultramicroscopy, 2010, 110, 935-945.

34 Dual-X Technology, https://www.thermofisher.com/sg/en/home/industrial/ele ctron-microscopy/electron-microscopy-instrumentsworkflow-solutions/dual-x-technology.html, (accessed 7 January 2020).

35 X. Llovet, C. J. Powell, F. Salvat and A. Jablonski, J. Phys. Chem. Ref. Data, 2014, 43, 13102.

36 QUANTAX FlatQUAD,

https://www.bruker.com/products/x-ray-diffraction-andelemental-analysis/eds-wds-ebsd-sem-micro-xrf-and-semmicro-ct/quantax-flatquad/technical-details.html, (accessed 7 January 2020).

37 J. Pritchard, L. Kesavan, M. Piccinini, Q. He, R. Tiruvalam, N. Dimitratos, J. A. Lopez-Sanchez, A. F. Carley, J. K. Edwards, C. J. Kiely and G. J. Hutchings, Langmuir, 2010, 26, 1656816577.

38 G. Cliff and G. W. Lorimer, J. Microsc., 1975, 103, 203-207.

39 D. Alloyeau, G. Prévot, Y. Le Bouar, T. Oikawa, C. Langlois, A. Loiseau and C. Ricolleau, Phys. Rev. Lett., 2010, 105, 255901.

40 D. Drouin, A. R. Couture, D. Joly, X. Tastet, V. Aimez and R. Gauvin, Scanning, 2007, 29, 92-101.

41 K. Tedsree, T. Li, S. Jones, C. W. A. Chan, K. M. K. Yu, P. A. J. Bagot, E. A. Marquis, G. D. W. Smith and S. C. E. Tsang, Nat. Nanotechnol., 2011, 6, 302-307.

42 P. Felfer, P. Benndorf, A. Masters, T. Maschmeyer and J. M. Cairney, Angew. Chemie - Int. Ed., 2014, 53, 11190-11193.

43 P. Felfer, T. Li, K. Eder, H. Galinski, A. P. Magyar, D. C. Bell, G. D. W. Smith, N. Kruse, S. P. Ringer and J. M. Cairney, Ultramicroscopy, 2015, 159, 413-419.

44 T. Li, P. A. J. Bagot, E. Christian, B. R. C. Theobald, J. D. B. Sharman, D. Ozkaya, M. P. Moody, S. C. E. Tsang and G. D. W. Smith, ACS Catal., 2014, 4, 695-702.

45 S. H. Kim, P. W. Kang, O. O. Park, J. B. Seol, J. P. Ahn, J. Y. Lee and P. P. Choi, Ultramicroscopy, 2018, 190, 30-38. S. H. Kim, J. Y. Lee, J. P. Ahn and P. P. Choi, Microsc. Microanal., 2019, 25, 438-446. 